\title{
Life-sustaining treatment preferences in older patients when referred to the emergency department for acute geriatric assessment: a descriptive study in a Dutch hospital
}

Daisy J. M. Ermers ${ }^{1 * \dagger}$ (D, Marit P. H. van Beuningen-van Wijk ${ }^{2+}$, Evi Peters Rit ${ }^{3}$, Sonja C. Stalpers-Konijnenburg ${ }^{4}$, Diana G. Taekema ${ }^{4}$, Frank H. Bosch ${ }^{5,6}$, Yvonne Engels $^{1}$ and Patricia J. W. B. van Mierlo ${ }^{4,7}$

\begin{abstract}
Background: In many cases, life-sustaining treatment preferences are not timely discussed with older patients. Advance care planning (ACP) offers medical professionals an opportunity to discuss patients' preferences. We assessed how often these preferences were known when older patients were referred to the emergency department (ED) for an acute geriatric assessment.
\end{abstract}

Methods: We conducted a descriptive study on patients referred to the ED for an acute geriatric assessment in a Dutch hospital. Patients were referred by general practitioners (GPs), or in the case of nursing home residents, by elderly care physicians. The referring physician was asked if preferences regarding life-sustaining treatments were known. The primary outcome was the number of patients for whom preferences were known. Secondary outcomes included which preferences, and which variables predict known preferences.

Results: Between 2015 and 2017, 348 patients were included in our study. At least one preference regarding lifesustaining treatments was known at referral in $45.4 \%$ (158/348) cases. In these cases, cardiopulmonary resuscitation (CPR) policy was always included. Preferences regarding invasive ventilation policy and ICU admission were known in 17\% (59/348) and 10.3\% (36/348) of the cases respectively. Known preferences were more frequent in cases referred by the elderly care physician than the GP $(P<0.001)$.

Conclusions: In less than half the patients, at least one preference regarding life-sustaining treatments was known at the time of referral to the ED for an acute geriatric assessment; in most cases it concerned CPR policy. We recommend optimizing ACP conversations in a non-acute setting to provide more appropriate, desired, and personalized care to older patients referred to the ED.

Keywords: Advance care planning, Palliative care, Emergency department, Geriatric assessment, Referral, Preferences regarding life-sustaining treatment

\footnotetext{
* Correspondence: daisy.ermers@radboudumc.nl

${ }^{\dagger}$ Daisy J. M. Ermers and Marit P. H. van Beuningen-van Wijk contributed equally to this work.

${ }^{1}$ Department of Anesthesiology, Pain and Palliative Medicine, Radboud university medical center, PO Box 9101, Nijmegen, HB 6500, The Netherlands Full list of author information is available at the end of the article
}

C C The Author(s). 2021 Open Access This article is licensed under a Creative Commons Attribution 4.0 International License, which permits use, sharing, adaptation, distribution and reproduction in any medium or format, as long as you give appropriate credit to the original author(s) and the source, provide a link to the Creative Commons licence, and indicate if changes were made. The images or other third party material in this article are included in the article's Creative Commons licence, unless indicated otherwise in a credit line to the material. If material is not included in the article's Creative Commons licence and your intended use is not permitted by statutory regulation or exceeds the permitted use, you will need to obtain permission directly from the copyright holder. To view a copy of this licence, visit http://creativecommons.org/licenses/by/4.0/ The Creative Commons Public Domain Dedication waiver (http://creativecommons.org/publicdomain/zero/1.0/) applies to the data made available in this article, unless otherwise stated in a credit line to the data. 


\section{Background}

An unplanned hospitalization necessitates in-themoment decision making. Advance care planning (ACP) recognizes that advance directives (ADs) play an important role and can be used at these decision making moments [1, 2]. ADs include preferences regarding life-sustaining treatments, for example interventions like cardiopulmonary resuscitation (CPR), which need to be considered or undertaken in case of an emergency [3].

ACP can either prevent unnecessary life-prolonging treatment [4] or undertreatment based on ageism. ACP is particularly recommended when individual health conditions worsen, especially in the case of older people [2] where the decisional capacity may decline at some stage $[5,6]$. Consequently, ACP should be discussed timely with older people when decisional capacity still exists; an emergency is not an ideal situation to discuss ACP [7]. Therefore, it is recommended that primary care physicians with longstanding doctor-patient relationships [8-10] timely discuss ACP with their patients [11].

In the Netherlands every citizen is registered with a general practitioner (GP); in nursing homes elderly care physicians take on this generalist role [12]. Both GPs and elderly care physicians are gatekeepers for hospital and specialist care. When a patient needs to be referred to the emergency department (ED), the GP or elderly care physician commonly contacts the relevant medical specialist by phone. For an acute geriatric assessment, they usually contact the geriatrician.

Although both GPs and elderly care physicians are aware of the relevance of having ACP conversations, treatment preferences often remain unknown for many individuals at the end of their lives $[13,14]$ or at the moment of referral to the ED.

We therefore initiated this study to assess how often and which preferences regarding life-sustaining treatments of older patients were known by the referring GP or elderly care physician at the time of referral to the ED for an acute geriatric assessment.

\section{Methods}

\section{Study design}

We performed a descriptive study at a clinical teaching hospital, Rijnstate, Arnhem, The Netherlands, a member of the association of tertiary teaching hospitals.

\section{Study setting and participants}

From June 2015 to January 2017, we included patients referred by the GP or elderly care physician to the ED for an acute geriatric assessment by an on-call geriatrician (geriatrician, geriatric intern or geriatric resident). The assessment is based on the principals of the comprehensive geriatric assessment (CGA) [15] which is used to examine (frail) older people with multimorbidity.

In the Netherlands, GPs and elderly care physicians maintain their own medical record system, which is not exchangeable with hospital medical records. Discussing and documenting life-sustaining treatment preferences is recommended in both primary and hospital care [16, 17]. These are based on recommendations for lifesustaining treatments defined in the Oxford Textbook of Palliative Medicine [18] and include cardiopulmonary resuscitation policy (CPR), admission to the intensive care unit (ICU) or coronary care unit (CCU), invasive ventilation, dialysis, defibrillation, and preferences regarding blood transfusion and antibiotics, or comfortfocused care. Conversations about these preferences mostly concern shared decision making; they are not one-sided physician decisions.

\section{Study procedure}

In May 2015, we discussed the study aim and procedure at a meeting with all geriatricians working at the hospital's geriatric department. We instructed them to ask each physician referring a patient to the ED for an acute geriatric assessment whether the patient's preferences regarding life-sustaining treatments were known. In cases where the referring physician was unaware of the preferences, they were asked to check whether these preferences were documented in the medical records or were known by the legal representative if he/she was present. To guide geriatricians when asking for known preferences, they were instructed to use the standard format in the patient's electronic medical record where physicians fill in treatment limitations regarding lifesustaining treatments. The answers were then documented in the hospital electronic medical record. For the duration of the study, the researchers regularly reminded the geriatricians of the procedure.

\section{Data collection}

Patient characteristics at the time of referral to the ED were collected. These included age, sex, living situation, mobility, presence of a cognitive disorder (evident from a diagnosis or reported by the referrer), Charlson comorbidity index (CCI) [19, 20], main reason for referral, and number of prescriptions. We also collected information regarding the number of hospitalizations in the year prior to the ED visit, as well as mortality during the ED visit or during the subsequent hospitalization.

The primary outcome was whether at least one preference regarding life-sustaining treatments was known. Secondary outcome measures included which preferences were known. Additionally, we noted the type of referrer (elderly care physician or GP), and analysed and corrected for the following patient-specific variables: age, 
sex, reason for referral, presence of a cognitive disorder, multimorbidity (CCI), mobility, use of home care, number of prescriptions, number of hospitalizations 1 year prior to the ED visit, and mortality during the ED visit or during the subsequent hospitalization. The medical records were reviewed retrospectively to collect data regarding the variables. Data were transcribed into Microsoft Excel and exported to SPSS. All data were anonymized.

\section{Ethics}

At the Rijnstate hospital, all patients are informed that routine registration data are anonymized and can be used for scientific research; they may choose to opt out. This study was performed following the Good Clinical Practice guidelines and the Dutch law (Wet op de Geneeskundige Behandelingsovereenkomst WGBO [21] and Wet Maatschappelijke Ondersteuning WMO [22]). Therefore, no permission of the medical ethical committee was required, including the need for written informed consent.

\section{Statistical analyses}

Statistical analyses were performed using IBM SPSS Statistics 24. We used descriptive statistics for all outcomes. We applied backward logistic regression to analyse the relation between patient and demographic characteristics, type of referrer and preferences being known. As independent variables, we used type of referrer and the following patient specific variables: age, sex, living situation, mobility, presence of a cognitive disorder, CCI, number of prescriptions, reason for referral and number of hospitalizations in the year before ED visit. As dependent variables, we used preferences being known. The criterion to stay in the model was $P<0.2$. We only present results for the final model of the backward logistic regression analysis.

\section{Results}

\section{Study sample}

Between May 2015 and January 2017, GPs and elderly care physicians referred a total of 501 patients to the ED for an acute geriatric assessment. In 348 cases (69.5\%), the on-call geriatrician asked and documented patient' preferences and data were collected. Of these patients, $69(19.8 \%)$ were referred by elderly care physicians and 279 (80.2\%) by GPs.

\section{Patient and demographic characteristics at time of referral to the ED}

Table 1 shows patient characteristics at time of referral to the ED. Mean age was 84 years, and more than half of the patients were women $(61.8 \% ; 215 / 348)$. Of all patients, $19.8 \%(69 / 348)$ lived in a nursing home. The other $80.2 \%$ (279/348) lived at home, of whom $63.1 \%$ (176/279) depended on home care or domestic services. Cognitive disorder was present in $60.6 \%(211 / 348)$ of the cases. For 243 (69.8\%) patients, it was their first ED visit that year. Mortality during the ED visit or during the subsequent hospitalization was $6.9 \%(24 / 348)$.

When comparing patients referred by the elderly care physician to those referred by GPs: walked independently $5.8 \%$ (4/69) vs. $23.7 \%$ (66/279); cognitive disorder present $87.0 \%(60 / 69)$ vs. $54.1 \%(151 / 279) ; \quad C C I \geq 3$ $52.2 \%(36 / 69)$ vs. $29.0 \%(81 / 279)$; > 5 prescriptions $92.8 \%$ $(64 / 69)$ vs. $69.8 \%(195 / 279)$ - all respectively.

These parameters show that our study population generally consisted of frail older people, those referred by the elderly care physician were even more frail.

\section{Preferences regarding life-sustaining treatments}

Preferences regarding life-sustaining treatments were known by the referring physician in $45.4 \%$ (158/348) of all patients. With regard to physician type, preferences were known in $88.4 \%(61 / 69)$ of patients referred by the elderly care physician, and in $34.8 \%$ (97/279) of patients referred by the GP. When preferences were known, they always included CPR policy (158/158), see Table 2. Of these 158 patients, invasive ventilation preferences were known in 59 cases (37.3\%), and ICU admission in 36 cases (22.8\%). Other preferences were rarely known (0.6-8.9\%). For patients referred by an elderly care physician, preferences regarding invasive ventilation and ICU admission were more often known compared to GP referrals; $44.3 \%$ (27/61) vs. $33.0 \%$ (32/97), and $27.9 \%$ (17/ $61)$ vs. $19.6 \%$ (19/97) respectively.

\section{Factors related to known preferences regarding life- sustaining treatments}

Table 3 shows the results of the final model of the backward logistic regression analysis for factors related to known preferences. Preferences were less frequently known for GP-referred patients (OR 0.075, $P<0.001$ ) and for patients aged between 60 and 74 (OR 0.171, $P<$ 0.05). Preferences were more frequently known for wheelchair-dependent patients (OR 3.02, $P<0.05$ ), those with a cognitive disorder (OR 1.96, $P<0.05$ ), and those hospitalized in the year before the ED visit (OR 2.48, $P<0.05)$. Supplementary Table 1 shows the known preferences stratified by type of referrer, and full patient and demographic characteristics.

\section{Discussion}

\section{Summary}

Our results show that in less than half of the referred older patients, at least one preference regarding lifesustaining treatments was known by the referring physician at the time of referral to the ED for an acute 
Table 1 Patient characteristics at time of referral, reason of referral and mortality during the ED visit or during the subsequent hospitalization ( $N=348)$, N (\%)

\begin{tabular}{|c|c|c|c|}
\hline & $\begin{array}{l}\text { Referred by elderly care physician, } \\
N=69\end{array}$ & $\begin{array}{l}\text { Referred by } G P \\
N=279\end{array}$ & $\begin{array}{l}\text { Total, } \\
N=348\end{array}$ \\
\hline \multicolumn{4}{|l|}{ Age, per category } \\
\hline $60-74$ & $10(14.5)$ & $22(7.9)$ & $32(9.2)$ \\
\hline $75-84$ & $26(37.7)$ & $110(39.4)$ & $136(39.1)$ \\
\hline $85-94$ & $28(40.6)$ & $135(48.4)$ & $163(46.8)$ \\
\hline$\geq 95$ years & $5(7.2)$ & $12(4.3)$ & $17(4.9)$ \\
\hline \multicolumn{4}{|l|}{ Sex } \\
\hline Female & $43(62.3)$ & $172(61.6)$ & $215(61.8)$ \\
\hline \multicolumn{4}{|l|}{ Living situation } \\
\hline Nursing home & $69(100)$ & - & $69(19.8)$ \\
\hline At home, with: & - & $279(100)$ & - \\
\hline - No home care services & - & $99(35.5)$ & $99(28.4)$ \\
\hline - Home care services & - & $176(63.1)$ & $176(50.6)$ \\
\hline - Unknown amount of services & - & $4(1.4)$ & $4(1.1)$ \\
\hline \multicolumn{4}{|l|}{ Mobility } \\
\hline \multicolumn{4}{|l|}{ Walking } \\
\hline - Independent & $4(5.8)$ & $66(23.7)$ & $70(20.1)$ \\
\hline - With walking aid (walking stick/wheeled walker) & $32(46.4)$ & $193(69.2)$ & $225(64.7)$ \\
\hline Wheelchair dependent & $31(44.9)$ & $14(5.0)$ & $45(12.9)$ \\
\hline Unknown & $2(2.9)$ & $6(2.2)$ & $8(2.3)$ \\
\hline \multicolumn{4}{|l|}{ Presence of a cognitive disorder } \\
\hline Yes & $60(87.0)$ & $151(54.1)$ & $211(60.6)$ \\
\hline No & $6(8.7)$ & $125(44.8)$ & $131(37.6)$ \\
\hline Unknown & $3(4.3)$ & $3(1.1)$ & $6(1.7)$ \\
\hline \multicolumn{4}{|l|}{ Charlson comorbidity index (CCl) } \\
\hline 0 & $1(1.4)$ & $36(12.9)$ & $37(10.6)$ \\
\hline $1-2$ & $32(46.4)$ & $160(57.3)$ & $192(55.2)$ \\
\hline$\geq 3$ & $36(52.2)$ & $81(29.0)$ & $117(33.6)$ \\
\hline Unknown & $0(0.0)$ & $2(0.7)$ & $2(0.6)$ \\
\hline \multicolumn{4}{|l|}{ Number of prescriptions } \\
\hline 0 & $0(0.0)$ & $5(1.8)$ & $5(1.4)$ \\
\hline $1-5$ & $3(4.3)$ & $78(28.0)$ & $81(23.3)$ \\
\hline $6-10$ & $22(31.9)$ & $114(40.9)$ & $136(39.1)$ \\
\hline $11-15$ & $28(40.6)$ & $63(22.6)$ & $91(26.1)$ \\
\hline$>15$ & $14(20.3)$ & $18(6.5)$ & $32(9.2)$ \\
\hline Unknown & $2(2.9)$ & $1(0.4)$ & $3(0.9)$ \\
\hline \multicolumn{4}{|l|}{ Category of the main reason for referral } \\
\hline Internal medicine & $31(44.9)$ & $105(37.6)$ & $136(39.1)$ \\
\hline Acute cognitive decline & $17(24.6)$ & $92(33.0)$ & 109 (31.3) \\
\hline Functional decline & $3(4.3)$ & $46(16.5)$ & $49(14.1)$ \\
\hline Pulmonological & $5(7.2)$ & $11(3.9)$ & $16(4.6)$ \\
\hline Neurological & $5(7.2)$ & $10(3.6)$ & $15(4.3)$ \\
\hline Psychiatric & $3(4.3)$ & $6(2.2)$ & $9(2.6)$ \\
\hline Chronic cognitive decline & $3(4.3)$ & $4(1.4)$ & $7(2.0)$ \\
\hline
\end{tabular}


Table 1 Patient characteristics at time of referral, reason of referral and mortality during the ED visit or during the subsequent hospitalization ( $N=348)$, N (\%) (Continued)

\begin{tabular}{|c|c|c|c|}
\hline & $\begin{array}{l}\text { Referred by elderly care physician, } \\
N=69\end{array}$ & $\begin{array}{l}\text { Referred by GP, } \\
N=279\end{array}$ & $\begin{array}{l}\text { Total, } \\
N=348\end{array}$ \\
\hline Cardiological & $2(2.9)$ & $5(1.8)$ & $7(2.0)$ \\
\hline \multicolumn{4}{|l|}{ Number of hospitalizations during one year before ED visit } \\
\hline 0 & $48(69.6)$ & $195(69.9)$ & $243(69.8)$ \\
\hline 1 & $13(18.8)$ & $50(17.9)$ & $63(18.1)$ \\
\hline$\geq 2$ & $8(11.6)$ & $34(12.2)$ & $42(12.1)$ \\
\hline Mortality during ED visit or during the subsequent hospitalization & $7(10.1)$ & $17(6.1)$ & $24(6.9)$ \\
\hline
\end{tabular}

geriatric assessment. Known preferences always concerned CPR policy, with invasive ventilation and ICU admission being mentioned occasionally. Elderly care physicians were more often aware of their patients' preferences regarding life-sustaining treatments. There are several possible reasons for this. Firstly, the Dutch quality framework of nursing home care [23] states that within $24 \mathrm{~h}$ of admission to a nursing home, a (draft) medical plan should be made including treatment limitations regarding CPR policy. Although national guidelines are in place to stimulate GPs to discuss these items with (frail) older people, this is not obligatory [16, 24]. Secondly, elderly care physicians have a regional medical records system in which an on-call physician can access all notes made by colleagues, in contrast to GPs who cannot always access patient medical records during out-ofhours services.

\section{Strengths and limitations}

To our knowledge, we are the first to assess the extent to which older patients' preferences regarding lifesustaining treatments when referred to the ED for an acute geriatric assessment are known by the referring physician. Moreover, we are the first to study determinants of the presence of these preferences at referral. Previous studies were merely performed in the United States [25-27], were mostly limited to patient-reported outcomes [28-30], or were not performed at referral

Table 2 Known patients' preferences regarding life-sustaining treatments at referral to the ED for an acute geriatric assessment. The study population is split by type of referrer. For patients for whom preferences were known, the frequencies of the individual preferences are presented

\begin{tabular}{|c|c|c|c|}
\hline & $\begin{array}{l}\text { Referred by elderly care physician, } \\
N=69\end{array}$ & $\begin{array}{l}\text { Referred by } G P, \\
N=279\end{array}$ & $\begin{array}{l}\text { Total, } \\
N=348\end{array}$ \\
\hline \multirow[t]{2}{*}{ Patients for whom at least one preference is known; $N(\%)$} & $61(88.4)$ & $97(34.8)$ & $158(45.4)$ \\
\hline & $\begin{array}{l}\text { Referred by elderly care physician, } \\
N=61\end{array}$ & $\begin{array}{l}\text { Referred by } G P \\
N=97\end{array}$ & $\begin{array}{l}\text { Total, } \\
N=158\end{array}$ \\
\hline Cardiopulmonary resuscitation (CPR) known; $N$ (\%) & $61(100)$ & $97(100)$ & $158(100)$ \\
\hline When known, preference 'yes'; $N$ & 4 & 10 & 14 \\
\hline Invasive ventilation known; $N$ (\%) & $27(44.3)$ & $32(33.0)$ & $59(37.3)$ \\
\hline When known, preference 'yes'; $N$ & 3 & 7 & 10 \\
\hline Admission to the intensive care unit (ICU) known; $N$ (\%) & $17(27.9)$ & 19 (19.6) & $36(22.8)$ \\
\hline When known, preference 'yes'; $N$ & 3 & 7 & 10 \\
\hline Admission to the coronary care unit (CCU) known; $N(\%)$ & $6(9.8)$ & $8(8.2)$ & $14(8.9)$ \\
\hline When known, preference 'yes'; $N$ & 2 & 7 & 9 \\
\hline Dialysis known; $N(\%)$ & $3(4.9)$ & $6(6.2)$ & $(5.7)$ \\
\hline When known, preference 'yes'; $N$ & 2 & 6 & 8 \\
\hline Defibrillation known; $N$ (\%) & $3(4.9)$ & $6(6.2)$ & $9(5.7)$ \\
\hline When known, preference 'yes'; $N$ & 2 & 6 & 8 \\
\hline Only comfort-focused care (no life-prolonging treatments) known; $N$ (\%) & $2(3.3)$ & $4(4.1)$ & $6(3.8)$ \\
\hline When known, preference 'yes'; $N$ & 0 & 3 & 3 \\
\hline Other preferences, including blood transfusion and antibiotics known; $N(\%)$ & $1(1.6)$ & $0(0.0)-$ & $1(0.6)$ \\
\hline When known, preference 'yes'; $N$ & 0 & - & 0 \\
\hline
\end{tabular}


Table 3 End model of backward logistic regression analysis for factors related to preferences being known

\begin{tabular}{|c|c|c|}
\hline Factor & OR $(95 \% \mathrm{Cl})$ & $P$-value \\
\hline \multicolumn{3}{|l|}{ Type of referrer } \\
\hline GP vs. elderly care physician & $0.075(0.029-0.192)$ & $<0.001$ \\
\hline Age (in years) & & 0.003 \\
\hline $60-74$ vs. $75-84$ & $0.171(0.050-0.581)$ & 0.005 \\
\hline $85-94$ vs. $75-84$ & $1.54(0.894-2.66)$ & 0.119 \\
\hline$\geq 95$ vs. $75-84$ & $0.468(0.118-1.86)$ & 0.281 \\
\hline Mobility & & 0.044 \\
\hline Unknown vs. walking independent & $0.203(0.021-1.94)$ & 0.166 \\
\hline $\begin{array}{l}\text { Walking with aid vs. walking } \\
\text { independent }\end{array}$ & $0.880(0.469-1.65)$ & 0.689 \\
\hline $\begin{array}{l}\text { Wheelchair dependent vs. } \\
\text { walking independent }\end{array}$ & $3.02(1.02-8.95)$ & 0.046 \\
\hline Presence of cognitive disorder & & 0.044 \\
\hline Yes vs. no & $1.96(1.16-3.33)$ & 0.012 \\
\hline Unknown vs no & $1.73(0.226-13.3)$ & 0.597 \\
\hline Hospitalization one year before ED visit & & 0.020 \\
\hline 1 vs. none & $2.48(1.28-4.79)$ & 0.007 \\
\hline$\geq 2$ vs. none & $1.67(0.764-3.63)$ & 0.199 \\
\hline
\end{tabular}

[31, 32]. A strength is our methodology; daily practice was best reflected by using a direct approach with the geriatrician asking the referring physician whether preferences were known.

We note a number of limitations. First, during the study period, we observed that in about one-third of the referrals, on-call geriatricians did not consistently ask each referrer whether life-sustaining treatment preferences were known. We had to remind the geriatricians that the study procedure was still ongoing. It is likely that in the majority of these cases, the geriatrician simply forgot to ask, due to, for example, a high workload. A second possibility is that the geriatrician forgot to document the answer when it concerned patients of whom the referring physician did not know preferences. This would have led to an overestimation of known preferences, while the extent to which preferences are known is already limited. A third reason may be that the on-call geriatrician did not feel the need to ask about known preferences; they may have been aware of the preferences regarding life-sustaining treatments or they expected that the acute geriatric assessment at the ED would not lead to hospitalization. As we did not collect data on reasons for geriatricians not asking about and/or documenting known preferences, we can only speculate. However, we found selection bias unlikely, and it does not change our conclusion.

Second, this study was performed in the Netherlands, the only country with elderly care medicine as a medical specialty. Therefore, generalizability is limited regarding settings similar to the Dutch healthcare system. However, other countries have systems where each citizen has a GP who functions as a gatekeeper. Future research should examine whether the extent to which preferences were known depends more on the setting or more on the medical specialism of the referring physician.

Third, we did not distinguish whether patients were referred by their own physician or by an on-call physician. In the latter case it is likely that the patients' preferences would be less known to the on-call GPs, as they may not have had access to the electronic medical records stored in the patients' own general practice. This in contrast to elderly care physicians who have a regional medical records system in which the on-call physician can access all notes made by colleagues. Moreover, we only asked the referring physician whether preferences were known, and we did not collect information on whether preferences had only been discussed or documented. Both could lead to an over- or underestimation of the known number of preferences. However, in a recent study [33] the percentage of discussing and documenting limitations on life-sustaining treatments was almost equal (73.1 and 70.7\% respectively). Additionally, it is important to note that only registered and accessible information can influence decision making by a physician other than the patients' own physician.

A final limitation is that we focused on preferences regarding life-sustaining treatments, while ACP is a dynamic process that goes beyond this [2]. It is also important to include goals of care [34]. However, especially in an acute setting, all practitioners should be aware of preferences regarding life-sustaining treatments in order to provide more appropriate, desired, and personalized care. Therefore, we focused on those preferences which conform to ACP guidelines in which it is recognized that $\mathrm{ADs}$ which concern preferences regarding life-sustaining treatments are important for in-themoment decision making [1].

\section{Comparison with existing literature}

We show that preferences regarding life-sustaining treatments were known in almost half of the patients being referred. Similar results can be found in the literature. A US cross-sectional study [27] was performed in which they assessed patient-reported completion of ACP and availability of ACP documentation. They characterized completion and availability of ACP among a subset of older patients at an academic ED with an integrated electronic health record. Among study patients, 59\% reported having completed some form of ACP: living will $52 \%$, healthcare power of attorney $54 \%$, do not resuscitate $38 \%$, and either medical orders for scope of treatment or physician orders for life-sustaining treatment 
$6 \%$. In a systematic review which only included US studies, patient-reported $\mathrm{AD}$ completion ranged from 21 to $53 \%$ [26]. ADs were only available to ED personal in 1$44 \%$ of cases. We also show that preferences regarding life-sustaining treatments were known in almost $35 \%$ of the patients referred by the GP. These results support a Dutch study where $60 \%$ of patients aged $\geq 75$ in general practice had thought about end-of-life treatment preferences, but an ACP conversation with the GP rarely occurred [33]. We also confirm that preferences are mainly limited to CPR policy, invasive ventilation, and ICU admission. A study in Dutch general practices showed that GPs documented CPR policy in $28 \%$ and IC policy in $4 \%$ of the patients with lung or colon cancer [35].

Our results also show that preferences were more frequently known at repeated ED referral than at first ED referral. A recently published study reports that ED visits trigger a revision of limitations of life-sustaining treatment in most adult palliative patients with solid tumours who died $<3$ months after their ED visit. Before the ED visit, limitations on life-sustaining treatments were discussed in $33.8 \%$ of the cases, but this increased during or after ED visits to $70.7 \%$ [36].

\section{Implications for research and/or practice}

Patient preferences were unknown by the referring physician for more than half of the older patients referred to the ED for an acute geriatric assessment. This has implications for clinical practice in (frail) older people as ACP (including ADs) guides care when a patient is incapacitated or unable to communicate. Without ACP and/or ADs, the patient's legal representative can be asked about the patients' preferences which may be experienced as a burden for the legal representative [37]. Moreover, during crises, there is little time to discuss ACP or locate ADs. For that reason, prior knowledge of preferences is valuable, as patients are then more likely to receive desired and appropriate care in line with their preferences and values.

In about half of rehospitalized patients, preferences were still unknown by the referring physician. We hypothesize that this information often gets lost during information transfer between healthcare professionals. Therefore, we recommend that discussed preferences always be explicitly documented, and if possible, communicated by phone and/or referral letters when a patient is transferred between primary and secondary care. Furthermore, we also recommend studying the perspectives of frail older people regarding the timing of $\mathrm{ACP}$ conversations and the content of those conversations, in order to contribute to the existing evidence on this topic [38, 39].

As physicians find it difficult to talk about end-of-life treatment preferences, we recommend that they be better trained to initiate ACP conversations; this was shown to be highly effective in a study on ACP by GPs with dementia patients [40]. It appears that barriers to initiate ACP conversations are lack of time, knowledge, and expertise [41], especially when it concerns frail older people [14]. The disease trajectory of frail older patients is characterized by prolonged deterioration and may be cut short by death after an acute event [42]. Therefore, estimating prognosis is difficult, resulting in delays in the conversation on treatment preferences [43], while hospitalization or an unclear prognosis are actually reasons to initiate ACP [44].

GPs and elderly care physicians are both in a position to initiate ACP conservations, as both have a long-term patient relationship and the ability to discuss this in a quiet place with sufficient time and without the need for direct decisions $[45,46]$. Preferably, these conversations should not take place at the ED. There are also several non-acute moments at a geriatric department in which ACP could be initiated or continued. A recent ED visit or hospitalization can be a trigger and reference to initiate ACP conversations [47] as referring to this recent situation makes the discussion more tangible. Moreover, geriatricians are experts when it comes to frailty and comorbidity. They possess knowledge that can support GPs and elderly care physicians in these ACP conversations. Therefore, geriatricians can also contribute to a consistent and clear transmural message; ACP should be a shared responsibility of professionals in primary and secondary care.

\section{Conclusions}

To conclude, we found that patient preferences were known by the referring physician in less than half of the older patients referred to the ED for an acute geriatric assessment. When known, these preferences were mainly limited to CPR policy, and occasionally to invasive ventilation and ICU admission. This limited knowledge of preferences may lead to less personalized care with unnecessary futile interventions, unwanted life-prolonging treatments, but also to undertreatment based on ageism. Therefore, ACP needs more attention in daily practice in order to provide more appropriate, desired, and personalized care to older patients in a non-acute setting.

\section{Supplementary Information}

The online version contains supplementary material available at https://doi. org/10.1186/s12877-020-02002-y.

Additional file 1: Supplementary Table 1. Known preferences stratified by type of referrer, and patient and demographic characteristics, $\mathrm{N}$ (yes/total) (\%)

\section{Abbreviations}

ACP: Advance Care Planning; AD(s): Advance Directive(s); CCl: Charlson Comorbidity Index; CCU: Coronary Care Unit; CPR: Cardiopulmonary 
Resuscitation; ED: Emergency Department; GP(s): General Practitioner(s); ICU: Intensive Care Unit; OR: Odds Ratio

\section{Acknowledgements}

The authors thank prof dr. K.C.P. Vissers (Anesthesiologist at the Radboud university medical center, Nijmegen) and dr. ir. E.M. Bronkhorst (statistician at the Radboud university medical center) for their contribution to this article.

\section{Authors' contributions}

MvBvW, EPR, SSK, DT, FB, YE, PvM contributed to the design and implementation of the research. MvBvW and EPR collected the data. DE performed the statistical analysis and wrote the manuscript with support from the other authors. All authors discussed the results, and read and approved the final manuscript.

\section{Funding}

There was no funding for this project.

\section{Availability of data and materials}

The datasets used and analysed during the current study are available from the corresponding author on reasonable request.

\section{Ethics approval and consent to participate}

At the Rijnstate hospital, all patients have been informed that routine registration data are anonymized and can be used for scientific research; if they don't want their data to be used, they can opt-out. This study was performed following Good Clinical Practice guidelines and the Dutch law (Wet op de Geneeskundige Behandelingsovereenkomst WGBO [21] and Wet Maatschappelijke Ondersteuning WMO [22]). Therefore, no permission of the medical ethical committee was required, including the need for written informed consent.

\section{Consent for publication}

Not applicable.

\section{Competing interests}

The authors declare that they have no competing interests.

\section{Author details}

'Department of Anesthesiology, Pain and Palliative Medicine, Radboud university medical center, PO Box 9101, Nijmegen, HB 6500, The Netherlands. ${ }^{2}$ Department of Pulmonology, Rijnstate, Arnhem, The Netherlands. ${ }^{3}$ Department of Geriatrics, Meander medical center, Amersfoort, The Netherlands. ${ }^{4}$ Department of Geriatrics, Rijnstate, Arnhem, The Netherlands. ${ }^{5}$ Department of Intensive Care Medicine, Rijnstate, Arnhem, The Netherlands. ${ }^{6}$ Department of Internal Medicine, Radboud university medical center, Nijmegen, The Netherlands. ${ }^{7}$ Center of Supportive and Palliative Care, Rijnstate, Arnhem, The Netherlands.

Received: 26 August 2020 Accepted: 29 December 2020

Published online: 14 January 2021

\section{References}

1. Sudore RL, Fried TR. Redefining the "planning" in advance care planning: preparing for end-of-life decision making. Ann Intern Med. 2010;153(4):25661.

2. Rietjens JAC, Sudore RL, Connolly M, van Delden JJ, Drickamer MA, Droger $M$, et al. Definition and recommendations for advance care planning: an international consensus supported by the European Association for Palliative Care. Lancet Oncol. 2017;18(9):e543-e51.

3. Molloy DW, Guyatt GH, Russo R, Goeree R, O'Brien BJ, Bedard M, et al. Systematic implementation of an advance directive program in nursing homes: a randomized controlled trial. JAMA. 2000;283(11):1437-44.

4. Brinkman-Stoppelenburg A, Rietjens JA, van der Heide A. The effects of advance care planning on end-of-life care: a systematic review. Palliat Med. 2014;28(8):1000-25.

5. Karlawish $\mathrm{JH}$, Schmitt FA. Why physicians need to become more proficien in assessing their patients' competency and how they can achieve this. J Am Geriatr Soc. 2000;48(8):1014-6.
6. Kim SY, Karlawish JH, Caine ED. Current state of research on decisionmaking competence of cognitively impaired elderly persons. Am J Geriatr Psychiatry. 2002;10(2):151-65.

7. Cruz-Carreras MT, Chaftari P, Viets-Upchurch J. Advance care planning: challenges at the emergency department of a cancer care center. Support Care Cancer. 2018;26(2):585-8.

8. Evans N, Costantini M, Pasman HR, Van den Block L, Donker GA, Miccinesi G, et al. End-of-life communication: a retrospective survey of representative general practitioner networks in four countries. J Pain Symptom Manag. 2014;47(3):604-19 e3.

9. Lum HD, Sudore RL, Bekelman DB. Advance care planning in the elderly. Med Clin North Am. 2015;99(2):391-403.

10. Spoelhof GD, Elliott B. Implementing advance directives in office practice. Am Fam Physician. 2012;85(5):461-6.

11. Kearley KE, Freeman GK, Heath A. An exploration of the value of the personal doctor-patient relationship in general practice. Br J Gen Pract. 2001:51(470):712-8.

12. Schols JM, Crebolder HF, van Weel C. Nursing home and nursing home physician: the Dutch experience. J Am Med Dir Assoc. 2004;5(3):207-12.

13. Evans N, Pasman HR, Vega Alonso T, Van den Block L, Miccinesi G, Van Casteren V, et al. End-of-life decisions: a cross-national study of treatment preference discussions and surrogate decision-maker appointments. PLoS One. 2013:8(3):e57965.

14. Meeussen K, Van den Block L, Echteld M, Bossuyt N, Bilsen J, Van Casteren V, et al. Advance care planning in Belgium and The Netherlands: a nationwide retrospective study via sentinel networks of general practitioners. J Pain Symptom Manag. 2011;42(4):565-77.

15. Parker SG, McCue P, Phelps K, McCleod A, Arora S, Nockels K, et al. What is Comprehensive Geriatric Assessment (CGA)? An umbrella review. Age Ageing. 2018:47(1):149-55.

16. Guldemond F, Ott B. Wind A. In: Toolkit Advance Care Planning mbt het levenseinde; 2017.

17. NHG; Verenso; NVAVG WPN, Federatie Medisch Specialisten. Leidraad voo het proces en uniform vastleggen van proactieve zorgplanning (advance care planning, ACP) naar aanleiding van de COVID-19-pandemie 2020 [Available from: https://palliaweb.nl/getmedia/420de26e-007e-4ab4-a224db416d4a7d33/Eindversie-leidraad-proactieve-zorgplanning-(ACP)_ 22102020.pdf.

18. Ko DN, Blinderman CD. Withholding and withdrawing life-sustaining treatment (including artificial nutrition and hydration). In: Oxford Textbook of Palliative Medicine. 5 ed. ed. Oxford: Oxford University Press; 2015. https://oxfordmedicine.com/view/10.1093/med/9780199656097.001.0001/ med-9780199656097-chapter-108. Accessed 4 Jan 2021.

19. Charlson ME, Pompei $P$, Ales KL, CR MK. A new method of classifying prognostic comorbidity in longitudinal studies: development and validation. J Chronic Dis. 1987;40(5):373-83.

20. Frenkel WJ, Jongerius EJ, Mandjes-van Uitert MJ, van Munster BC, de Rooij SE. Validation of the Charlson Comorbidity Index in acutely hospitalized elderly adults: a prospective cohort study. J Am Geriatr Soc. 2014;62(2):342-6.

21. KNMG. Behandelingsovereenkomst [Available from: https://www.knmg.nl/ advies-richtlijnen/dossiers/behandelingsovereenkomst.htm.

22. Rijksoverheid. Wet maatschappelijke ondersteuning (Wmo) [Available from: https://www.rijksoverheid.nl/onderwerpen/zorg-en-ondersteuning-thuis/ wmo-2015.

23. Kwaliteitskader Verpleeghuiszorg. Samen leren en verbeteren. In: Zorginstituut Nederland; 2017.

24. Multidisciplinaire Richtlijn, Besluitvorming over reanimatie, Anticiperende besluitvorming over reanimatie bij kwetsbare ouderen: Verenso; 2013.

25. Baker EF, Marco CA. Advance directives in the emergency department. J Am Coll Emerg Physicians Open. 2020;1(3):270-5.

26. Oulton J, Rhodes SM, Howe C, Fain MJ, Mohler MJ. Advance directives for older adults in the emergency department: a systematic review. J Palliat Med. 2015;18(6):500-5.

27. Platts-Mills TF, Richmond NL, LeFebvre EM, Mangipudi SA, Hollowell AG, Travers D, et al. Availability of Advance Care Planning Documentation for Older Emergency Department Patients: A Cross-Sectional Study. J Palliat Med. 2017;20(1):74-8.

28. Gamertsfelder EM, Seaman JB, Tate J, Buddadhumaruk P, Happ MB. Prevalence of Advance Directives Among Older Adults Admitted to Intensive Care Units and Requiring Mechanical Ventilation. J Gerontol Nurs. 2016;42(4):34-41. 
29. Rao JK, Anderson LA, Lin FC, Laux JP. Completion of advance directives among U.S. consumers. Am J Prev Med. 2014;46(1):65-70.

30. Taylor DM, Ugoni AM, Cameron PA, McNeil JJ. Advance directives and emergency department patients: ownership rates and perceptions of use. Intern Med J. 2003;33(12):586-92.

31. Manu ER, Mody L, McNamara SE, Vitale CA. Advance Directives and Care Received by Older Nursing Home Residents. Am J Hosp Palliat Care. 2017; 34(2):105-10.

32. Sommer S, Marckmann G, Pentzek M, Wegscheider K, Abholz HH, in der Schmitten J. Advance directives in nursing homes: prevalence, validity, significance, and nursing staff adherence. Dtsch Arztebl Int. 2012;109(37): 577-83.

33. Verhoef MJ, de Nijs E, Horeweg N, Fogteloo J, Heringhaus C, Jochems A, et al. Palliative care needs of advanced cancer patients in the emergency department at the end of life: an observational cohort study. Support Care Cancer. 2020;28(3):1097-107. https://doi.org/10.1007/s00520-019-04906-X.

34. Gilissen J, Pivodic L, Gastmans C, Vander Stichele R, Deliens L, Breuer E, et al. How to achieve the desired outcomes of advance care planning in nursing homes: a theory of change. BMC Geriatr. 2018;18(1):47.

35. van der Plas A, Eliel M, Onwuteaka-Philipsen B. Advance care planning in de huisartsenpraktijk. In: Tijdschr voor Ouderengeneeskd; 2017.

36. Ermers DJM, van Bussel KJH, Perry M, Engels Y, Schers HJ. Advance care planning for patients with cancer in the palliative phase in Dutch general practices. Fam Pract. 2019;36(5):587-93.

37. Hickman RL Jr, Pinto MD. Advance directives lessen the decisional burden of surrogate decision-making for the chronically critically ill. J Clin Nurs. 2014;23(5-6):756-65

38. Mignani V, Ingravallo F, Mariani E, Chattat R. Perspectives of older people living in long-term care facilities and of their family members toward advance care planning discussions: a systematic review and thematic synthesis. Clin Interv Aging. 2017;12:475-84

39. Sharp T, Moran E, Kuhn I, Barclay S. Do the elderly have a voice? Advance care planning discussions with frail and older individuals: a systematic literature review and narrative synthesis. Br J Gen Pract. 2013;63(615):e65768.

40. Tilburgs B, Koopmans R, Vernooij-Dassen M, Adang E, Schers H, Teerenstra $S$, et al. Educating Dutch General Practitioners in Dementia Advance Care Planning: A Cluster Randomized Controlled Trial. J Am Med Dir Assoc. 2019.

41. De Vleminck A, Houttekier D, Deliens L, Vander Stichele R, Pardon K. Development of a complex intervention to support the initiation of advance care planning by general practitioners in patients at risk of deteriorating or dying: a phase 0-1 study. BMC Palliat Care. 2016;15:17.

42. Murray SA, Kendall M, Boyd K, Sheikh A. Illness trajectories and palliative care. BMJ. 2005;330(7498):1007-11.

43. Elliott M, Nicholson C. A qualitative study exploring use of the surprise question in the care of older people: perceptions of general practitioners and challenges for practice. BMJ Support Palliat Care. 2017;7(1):32-8.

44. Lloyd A, Kendall M, Starr JM, Murray SA. Physical, social, psychological and existential trajectories of loss and adaptation towards the end of life for older people living with frailty: a serial interview study. BMC Geriatr. 2016; 16(1):176.

45. De Vleminck A, Houttekier D, Pardon K, Deschepper R, Van Audenhove C, Vander Stichele R, et al. Barriers and facilitators for general practitioners to engage in advance care planning: a systematic review. Scand J Prim Health Care. 2013;31(4):215-26.

46. Michiels E, Deschepper R, Van Der Kelen G, Bernheim JL, Mortier F, Vander Stichele $\mathrm{R}$, et al. The role of general practitioners in continuity of care at the end of life: a qualitative study of terminally ill patients and their next of kin. Palliat Med. 2007;21(5):409-15.

47. Scheerens C, Deliens L, Van Belle S, Joos G, Pype P, Chambaere K. "A palliative end-stage COPD patient does not exist": a qualitative study of barriers to and facilitators for early integration of palliative home care for end-stage COPD. NPJ Prim Care Respir Med. 2018;28(1):23.

\section{Publisher's Note}

Springer Nature remains neutral with regard to jurisdictional claims in published maps and institutional affiliations.

\section{Ready to submit your research? Choose BMC and benefit from:}

- fast, convenient online submission

- thorough peer review by experienced researchers in your field

- rapid publication on acceptance

- support for research data, including large and complex data types

- gold Open Access which fosters wider collaboration and increased citations

- maximum visibility for your research: over $100 \mathrm{M}$ website views per year

At BMC, research is always in progress.

Learn more biomedcentral.com/submissions 